\title{
Chronic migraine patients show cognitive impairment in an extended neuropsychological assessment
}

\author{
Pacientes com migrânea crônica apresentam déficits cognitivos em uma avaliação \\ neuropsicológica estendida
}

Karen S. Ferreira', Caroliny T. Teixeira', Carolina Cáfaro', Gabriela Z. Oliver', Gabriela L. P. Carvalho', Larissa A. S. D. Carvalho', Brenda G. Silva', Fernanda B. B. Haes ${ }^{1}$, Marcelo C. Ciciarelli ${ }^{1}$

\begin{abstract}
The objective of the present study was to assess the presence of cognitive deficits in patients with chronic migraine, and to assess the main factors that trigger cognitive disorders, such as comorbidities or the use of medications. Methods: Chronic migraine and control groups were interviewed in a case-control study. The frequency and intensity of the headache, medication used and associated comorbidities were determined. All patients were submitted to an extended neuropsychological assessment. Results: The chronic migraine group $(n=30)$ had a worse performance in the Montreal Cognitive Assessment Test $(p=0.00)$, Verbal Fluency $(p=0.00)$, Stroop $(p=0.00)$, Clock Drawing Test $(p=0.00)$, Digit Span $(p=0.00)$ and Matrix Reasoning $(p=0.01$ ). After statistical adjustment by linear regression, migraine continued to be the only relevant factor in the poorer performance in the Montreal Cognitive Assessment, Verbal Fluency, Clock Drawing and Stroop tests. Conclusion: Patients with chronic migraine have cognitive deficits in multiple tasks, regardless of the presence of comorbidities or the use of medications.
\end{abstract}

Keywords: headache; migraine disorders; cognitive dysfunction.

\section{RESUMO}

O objetivo do presente estudo foi avaliar a presença de déficits cognitivos em pacientes com migrânea crônica e avaliar os principais fatores que desencadeiam transtornos cognitivos, como comorbidades e uso de medicações. Métodos: Pacientes com migrânea crônica $(n=30)$ e controles foram entrevistados, em um estudo caso-controle. A frequência e intensidade da cefaleia, medicações utilizadas e comorbidades associadas foram determinadas. Todos os pacientes foram submetidos a uma avaliação neuropsicológica estendida. Resultados: Os pacientes com migrânea crônica apresentaram uma pior performance no Montreal Cognitive Assessment ( $p=0.00)$, Fluência Verbal ( $p$ $=0.00)$, Teste de Stroop ( $p=0.00)$, Teste do Relógio $(p=0.00)$, Subteste Dígitos $(p=0.00)$ e Raciocínio matricial da WAIS-III ( $p=0.01)$. Após ajuste estatístico através de Regressão Linear, a migrânea se manteve como único fator relevante para pior desempenho em MoCA, Fluência verbal, Teste do relógio e Teste de Stroop. Conclusão: Pacientes com migrânea crônica apresentam déficits cognitivos incluindo múltiplas tarefas, independentes da presença de comorbidades e uso de medicações.

Palavras-chave: cefaleia; transtornos de enxaqueca; disfunção cognitiva.

In general, chronic migraine (CM) is a frequent symptom in the population ${ }^{1,2,3}$. In Brazil, epidemiological studies of CM have shown a prevalence of $5.12 \%^{4}$. CM is a type of headache that fulfills the criteria of migraine with or without aura of the International Headache Society, and persists for more than 15 days per month over at least three consecutive months ${ }^{3}$. The chronification of pain involves not only a specific period of time, but also changes in pain modulation at the brain and brainstem level that develops in patients affected by the disease. Functional imaging research has reported that CM may be associated with metabolic, functional, and structural abnormalities in the brainstem ${ }^{5}$. Besides this, patients experiencing migraine chronification may report increased non-headache pain, fatigue, psychiatric disorders and other somatic conditions associated with their long-term experience with migraine pain 6 .

Several studies have looked at the association between migraine and cognitive function but results from these studies are mixed. Some cross-sectional studies found no differences between migraine patients and controls ${ }^{7,8,9,10,11}$, while

${ }^{1}$ Centro Universitário Barão de Mauá, Faculdade de Medicina, Neurologia Clínica, Ribeirão Preto SP, Brasil.

Correspondence: Karen S. Ferreira; Departamento de Neurologia, Centro Universitário Barão de Mauá; Rua Ramos de Azevedo, 423 ; $14090-180$ Ribeirão Preto SP, Brasil.E-mail:karen.ferreira@baraodemaua.br

Conflict of Interest: There is no conflict of interest to declare.

Received 21 December 2017; Received in final form 24 April 208; Accepted 23 May 2018. 
others found evidence of worse cognitive performance among migraine patients ${ }^{12,13,14,15}$. A variety of tests were used to assess cognitive function and many of these studies were small, which may limit their ability to detect differences between those with and without migraine. None of them evaluated CM.

A multicenter prospective cohort study, which aimed to investigate factors associated with the development and progression of cardiovascular disease, evaluated participants for migraine with and without aura and for cognitive function. Three cognitive tests were used in this study: the Consortium to Establish a Registry for Alzheimer's Disease word list memory test, the Semantic Fluency Test and the Trail Making Test. Migraine without aura was associated with poorer cognitive performance, but CM was not evaluated specifically ${ }^{15}$.

One study analyzed the performance of patients with $\mathrm{CM}$ in cognitive tests comparing them with healthy controls. However, the cited study did not analyze in depth the influence of factors such as psychiatric disorders, sleep disorders or the use of medications ${ }^{12}$. Important confounding factors are detected when patients with migraine and cognitive complaints are evaluated. First of all, depressive disorders or anxiety disorders were involved in many of these patients, comorbidities related to attention deficits and to impaired performance in cognitive tests. Second, some medications frequently taken by patients with migraine, such as topiramate, have been proven to cause cognitive deficits ${ }^{16,17}$.

Rist and Kurth ${ }^{18}$ and Rist et al. ${ }^{19}$ presented results for the association between migraine and cognitive decline over time, in elderly men and women. Participants reported a lifetime history of migraine in the past, and they were assessed for cognitive function (mean age of 69 years). The authors found no evidence that migraine was associated with faster cognitive decline over time.

Thus, considering the importance of this subject, and the differences among previous studies, the objective of the present study was to evaluate the presence of cognitive deficits in patients with CM, compared to control patients without migraine. An additional objective was to assess the main factors that trigger cognitive disorders in the population with $\mathrm{CM}$, such as depressive disorder, anxiety disorder, use of medications acting on the central nervous system as topiramate, non-repairing sleep, alcohol abuse, a history of head trauma, and other comorbidities. Based on the results, it would be possible to outline strategies for a better approach to cognitive disorders in patients with $\mathrm{CM}$.

\section{METHODS}

A descriptive cross-sectional study was conducted by interviewing patients treated at a Neurology Clinic from a School of Medicine in Brazil. Patients of both sexes, aged 18 to 60 years with $\mathrm{CM}$ with or without aura according to the criteria of the International Headache Society, who gave written informed consent to participate, were included in the study. Exclusion criteria were the presence of diagnosed dementia, organic brain dysfunction (including neurological diseases that influence cognitive function and head trauma) or illiteracy and age older than 60 years.

Each patient was interviewed personally for the evaluation of demographic and clinical data and for the application of neuropsychological tests for cognitive evaluation. Individuals matched for sex, age and schooling, with no diagnosis of migraine were used as controls.

\section{Clinical data}

Data regarding age, sex, diagnosis of headache, frequency and intensity of headache attacks, doses of daily medications and use of analgesics were obtained during the interview. The patients were also assessed for comorbidities such as depressive and anxiety disorders (Diagnostic and Statistical Manual of Mental Disorders - DSM-5) ${ }^{20}$, sleep aspects ("Do you have any kind of sleep problems such as insomnia, unrefreshed sleep or sleep apnea?"), alcohol abuse ("How many glasses of alcohol do you drink weekly?), history of head trauma ("Have you ever had any kind of head trauma?"), and other comorbidities that were previously diagnosed by other clinicians such as thyroid dysfunction, diabetes and hypertension. They were also questioned about the impact of these conditions on their life.

Patients and controls were then submitted to neuropsychological evaluation, including the Montreal Cognitive Assessment (MoCA) test validated for the Portuguese language $^{21}$; Verbal Fluency Test; Stroop Test (for attention and working memory) ${ }^{22}$; Color Trails Test ${ }^{23}$; Wechsler Adult Intelligence Scale (WAIS-III) Digit Span (digits forward), Vocabulary and Matrix Reasoning ${ }^{24}$; Rey Auditory Verbal Learning Test (RAVLT) ${ }^{25}$; the Beck Depression Inventory ${ }^{26}$; and the Beck Anxiety Inventory ${ }^{27}$.

\section{Statistical analysis}

Data were analyzed using the SPSS software, version $18.0^{28}$. The Chi-square test or Fisher's exact test was applied for the analysis of the categorical variables according to the expected frequency in the cells. The Kolmogorov-Smirnov test was applied for the analysis of numerical variables in order to define the type of variable distribution. Data with normal distribution were analyzed by parametric tests such as the Student's $t$ test or analysis of variance (ANOVA) and data with non-normal distribution were analyzed by the Mann-Whitney test. Binary logistic regression and linear regression were used to correlate two or more variables.

\section{Ethical aspects}

The study was approved by the Ethics Committee of the University Center Barão de Mauá, Brazil, CAAE 38707014.3.0000.5378. 


\section{RESULTS}

A total of 73 individuals were preselected and 13 of them were excluded. Of these, three were selection failures (one was older than 60 years, one was younger than 18 years, one no longer had $\mathrm{CM}$ ), one did not complete the tests and nine withdrew their consent to participate in the study. Finally, 60 subjects were included in the study, 30 of them with CM and 30 as healthy controls.

Of the patients assigned to the CM group, 29 (96.7\%) were female, and the same distribution occurred in the control group (CG), with 29 females (96.7\%). The mean age was 33.7 years for both the CM (SD 11.2) and the CG (SD 9.7) groups. Regarding schooling, 10 patients in the CM group (33.3\%) had completed high school and 20 (66.7\%) had higher education. Similarly, in the CG, 10 had completed high school and $20(66.7 \%)$ had higher education. Fifteen CM patients $(50 \%)$ and 11 CG subjects (36.7\%) were married (Table 1$)$.

Among the CM patients, pain was pulsatile in 19 (63.3\%). Associated characteristics were nausea in $26(86.6 \%)$ patients, photophobia in 27 (90\%) and phonophobia in 24 (80\%). The mean $( \pm$ SD) total time of pain was $14.7 \pm 11.3$ years. The mean current frequency of pain was $12.0 \pm 9.2$ days/month. The mean pain intensity, according to the numerical pain scale, was $8.5 \pm$ 1.9. Pain disrupted the daily activity of all 30 (100\%) patients and caused absenteeism from work in 22 (73.3\%) (Table 2).

Fifteen CM patients (50\%) took topiramate, four (13.2\%) took tricyclic antidepressants, four (13.2\%) took pregabalin, one (33\%) took valproic acid, two (6.6\%) took beta-blockers, and two (6.6\%) took muscle relaxants. The analgesics most frequently used were nonhormonal anti-inflammatory drugs ( $\mathrm{n}=6$ [19.8\%]), triptans $(\mathrm{n}=9[27.7 \%])$, and chlorpromazine $(\mathrm{n}=4[13.2 \%])$. The frequency of analgesic use was 8.2 days/month. Only seven $(23.1 \%)$ patients took analgesics in an abusive manner.

Among the CG subjects, the medications most frequently used were selective serotonin re-uptake antidepressants $(\mathrm{n}=$ $1[3.3 \%])$, sleep inducers $(n=1[3.3 \%])$ and anti-hypertensive $\operatorname{drugs}(n=3[10 \%])$.

The most frequent comorbidities observed in the CM group were generalized anxiety disorder $(n=21$ [70\%]), major depressive disorder ( $n=6[20 \%])$, non-repairing sleep $(n=16$ [53.3\%]), and hypothyroidism ( $\mathrm{n}=1$ [3.3\%]). No patients had hypertension, diabetes, previous head trauma, epilepsy, or alcohol abuse.

The most frequent comorbidities observed in the CG were generalized anxiety disorder $(n=8[26.7 \%])$, major depressive disorder ( $n=4$ [13.3\%]), non-repairing sleep ( $n=7$ [23.3\%]), hypertension $(n=2[6.6 \%])$, and diabetes $(n=1[3.3 \%])$. No CG subject reported previous head trauma, hypothyroidism, epilepsy or alcohol abuse.

According to the DSM-5 criterion for major depressive disorder and generalized anxiety disorder, there was no significant relationship between CM and major depressive disorder ( $p=0.73$ ), but CM was significantly related to generalized anxiety disorder $(\mathrm{p}=0.00)$.

According to the Beck Depression Inventory, and Beck Anxiety Inventory, there was a relationship between CM and the Beck Depression Inventory scores $(p=0.01)$ and the Beck Anxiety Inventory scores $(\mathrm{p}=0.01)$. CM was also related to non-repairing sleep $(\mathrm{p}=0.03)$.

Twenty-two of the patients with CM (73.3\%) had memory complaints, as opposed to only one (3.3\%) of the controls.

Regarding the cognitive tests applied, the following mean results are listed in Table 3.

There was no relationship between the use of topiramate and performance in the MoCA test $(\mathrm{p}=0.28$, Mann Whitney test), Clock Drawing Test $(\mathrm{p}=0.35)$, Vocabulary $(\mathrm{p}=0.39)$, Color Trails Test $(p=0.89)$, or RAVLT $(p=0.82)$. There was a relationship between the use of topiramate and the Verbal Fluency Test $(p=0.00)$, Stroop Test $(p=0.00)$, Matrix Reasoning $(p=0.03)$ and Digit Span $(p=0.00)$, according to the Mann Whitney test.

To assess patient performance in the MoCA and the possible factors involved in the results, a linear regression model was used, controlled for the variables of CM, major depressive disorder, generalized anxiety disorder, non-repairing sleep and use of topiramate. The CM variable was an independent factor for the worst MoCA results; a result that was maintained when the use of topiramate was included in the model (Table 4).

Assessment of patient performance in the Verbal Fluency Test, Clock Drawing Test, Stroop Test, Color Trails Test, WAIS-III Digit Span, Vocabulary and Matrix Reasoning, and the RAVLT were repeated in order to clarify the results, using linear regression models, controlled for the variables of CM, major depressive disorder, generalized anxiety disorder, nonrepairing sleep and use of topiramate. The CM variable was an independent factor for the worse results in the Verbal Fluency Test, Clock Drawing Test and Stroop Test (Table 5). The group taking topiramate also showed a poorer performance in the Digit Span and in the Vocabulary tests.

Table 1. Demographic data of patients with chronic migraine (CM) and controls (CG).

\begin{tabular}{lcc}
\hline Variable & CM / $n=30$ & CG / n = 30 \\
\hline Mean age & $33.7(\mathrm{SD} \pm 11.2)$ & $33.7(\mathrm{SD} \pm 9.7)$ \\
Gender & $29(96.7 \%)$ women & $29(96.7 \%)$ women \\
Marital status & $15(50 \%)$ married & 1.79 \\
High school educational level & $10(33.3 \%)$ & 0.37 \\
Higher education & $20(66.7 \%)$ & $10(33.3 \%)$ \\
\hline SD: standard deviation & & $20(66.7 \%)$
\end{tabular}




\section{DISCUSSION}

In the present study, patients with $\mathrm{CM}$ showed a poorer performance than controls in the MoCA test. According to an adjusted linear regression model, this result was not influenced by the use of topiramate or the main comorbidities involved in the results. CM patients also showed a poorer performance than the CG in the Verbal Fluency, Clock Drawing Test, Stroop Test, WAIS-III Digit Span and the WAIS-III Matrix Reasoning. When the results were adjusted using a linear regression model, the presence of CM continued to be an independent factor influencing the results of the Verbal Fluency, Clock Drawing Test and Stroop Test, but not of the other tests, indicating that other factors influence this relationship. These data indicate significant impairment of cognition caused specifically by CM, including language use (Verbal Fluency Test), visuospatial skills (Clock Drawing Test), and attention (Stroop Test).

Comorbidities such as non-repairing sleep and the use of topiramate elicited the worst results in patients with CM in the WAIS-III Digit Span. In the WAIS-III Matrix Reasoning test, depressive disorder was the main independent factor for worse results.

The poorer performance of the patients taking topiramate in the Digit Span, which evaluates short-term memory,

Table 2. Characteristics of migraine in patients with chronic migraine.

\begin{tabular}{|c|c|}
\hline Characteristics & Frequency - mean ( \pm SD) \\
\hline Pulsatile & $19(63.3 \%)$ \\
\hline Nausea & $26(86.6 \%)$ \\
\hline Photophobia & $27(90 \%)$ \\
\hline Phonophobia & $24(80 \%)$ \\
\hline Aura & $1(3.3 \%)$ \\
\hline Use of topiramate & $15(50 \%)$ \\
\hline Disruption of activities & $30(100 \%)$ \\
\hline Absenteeism from work & $22(73.3 \%)$ \\
\hline Mean headache intensity* & $8.5(S D 1.9)$ \\
\hline Total time of migraine pain (in years) & 14.7 (SD 11.3) \\
\hline Frequency (days/month) & $12.0($ SD 9.2) \\
\hline
\end{tabular}

is understandable within a clinical context. Patients taking topiramate seem to have an attention deficit, as also reported in previous studies ${ }^{16,17}$.

Although the scientific literature has frequently reported a poorer performance by patients with depressive disorder in cognitive tests, in the present study only the WAIS-III Matrix Reasoning test was influenced by this comorbidity. In addition, anxiety disorder was a factor of influence on the Vocabulary Test, associated with the use of topiramate.

How can we explain these findings? The topic of cognition and chronic pain has recently been reported in the search for possible reasons for a poor performance in cognitive tests by patients with chronic pain, such as the presence of depressive symptoms (which is detected in $40 \%$ to $50 \%$ of patients with chronic pain) and the use of medications ${ }^{29}$.

A previous study ${ }^{30}$ reported that the patients with chronic pain had a poorer performance in the MoCA instrument (total score), Verbal Fluency Test, Clock Drawing Test and Stroop Test. The group with chronic pain also had a higher

Table 3. Mean scores in neuropsychological tests for patients with chronic migraine (CM) and controls (CG)

\begin{tabular}{|c|c|c|c|}
\hline Test & $\begin{array}{c}\mathrm{CM} \\
\mathrm{n}=30\end{array}$ & $\begin{array}{c}C G \\
n=30\end{array}$ & $\mathrm{p}$-value \\
\hline $\mathrm{MoCA}^{*}$ & 24.4 & 26.7 & 0.00 \\
\hline Verbal Fluency & 13.7 & 19.1 & 0.00 \\
\hline Clock Drawing Test & 2.2 & 2.7 & 0.00 \\
\hline 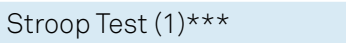 & 14.3 & 11.6 & 0.00 \\
\hline 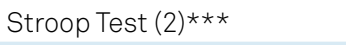 & 17.9 & 14.3 & 0.01 \\
\hline Stroop Test (3)*** & 24.5 & 18.8 & 0.00 \\
\hline RAVLT & 49.5 & 50.8 & 0.70 \\
\hline WAIS-III Matrix Reasoning & 17.8 & 18.9 & 0.01 \\
\hline Color Trail Test $1 * \star \star$ & 47.7 & 45.3 & 0.38 \\
\hline 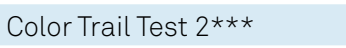 & 92.8 & 79.7 & 0.24 \\
\hline WAIS-III Digit Span & 13.0 & 15.8 & 0.00 \\
\hline WAIS-III Vocabulary & 35.1 & 37.4 & 0.23 \\
\hline Beck Depression Inventory & 10.2 & 6.8 & 0.01 \\
\hline Beck Anxiety Inventory & 11.9 & 6.2 & 0.01 \\
\hline
\end{tabular}

RAVLT: Rey Auditory Verbal Learning Test; WAIS-III: Wechsler Adult Intelligence Scale;*MoCA: Montreal Cognitive Assessment; **MannWhitney test $* * *$ seconds.

Table 4. Linear regression model in which the MoCA test was the dependent variable, controlled by the independent variables chronic migraine, use of topiramate, major depressive disorder, generalized anxiety disorder, and nonrepairing sleep.

\begin{tabular}{|c|c|c|c|c|}
\hline Model & Unstandardized coefficients B & Std error & $\mathrm{p}$-value & $95 \% \mathrm{Cl}$ for $\mathrm{B}$ \\
\hline Chronic migraine & 2.26 & 0.66 & 0.00 & $0.94-3.59$ \\
\hline Depressive disorder & -1.20 & 0.91 & 0.19 & $-3.03-0.61$ \\
\hline Generalized anxiety disorder & 0.28 & 0.83 & 0.73 & $-1.38-1.95$ \\
\hline Nonrepairing sleep & -0.47 & 0.77 & 0.54 & $-2.02-1.07$ \\
\hline \multicolumn{5}{|c|}{ Second model with the addition of topiramate } \\
\hline Chronic migraine & 2.47 & 0.76 & 0.00 & $0.92-4.01$ \\
\hline Use of topiramate & -0.45 & 0.86 & 0.60 & $-2.20-1.28$ \\
\hline Depressive disorder & -1.18 & 0.91 & 0.20 & $-3.02-0.65$ \\
\hline Generalized anxiety disorder & 0.22 & 0.85 & 0.79 & $-1.47-1.92$ \\
\hline Nonrepairing sleep & -0.37 & 0.79 & 0.63 & $-1.98-1.22$ \\
\hline
\end{tabular}


Table 5. Linear regression model in which Verbal Fluency, Clock Drawing Test, Stroop Test, Rey Auditory Verbal Learning Test, WAIS-III Matrix Reasoning, Color Trails Test, and WAIS-III Digit Span and Vocabulary were the dependent variables, controlled with the independent variables chronic migraine, use of topiramate, major depressive disorder, generalized anxiety disorder and nonrepairing sleep.

\begin{tabular}{lccccc}
\hline Test & Migraine & $\begin{array}{c}\text { Use of } \\
\text { topiramate }\end{array}$ & $\begin{array}{c}\text { Major depressive } \\
\text { disorder }\end{array}$ & $\begin{array}{c}\text { Generalized } \\
\text { anxiety disorder }\end{array}$ & $\begin{array}{c}\text { Nonrepairing } \\
\text { sleep }\end{array}$ \\
\hline Verbal fluency & $0.00^{*}$ & 0.40 & 0.10 & 0.11 & 0.62 \\
Clock drawing test & 0.00 & 0.48 & 0.48 & 0.99 & 0.55 \\
Stroop test (1) & 0.06 & 0.06 & 0.12 & 0.80 & 0.28 \\
Stroop test (2) & 0.01 & 0.23 & 0.88 & 0.08 & 0.08 \\
\hline Stroop test (3) & 0.03 & 0.43 & 0.75 & 0.92 & 0.08 \\
RAVLT & 0.41 & 0.34 & 0.98 & 0.65 & 0.59 \\
WAIS-III: Matrix reasoning & 0.11 & 0.35 & 0.01 & 0.97 & 0.59 \\
Color trail test & 0.92 & 0.91 & 0.12 & 0.46 & 0.30 \\
WAIS-III: Digit span & 0.16 & 0.05 & 0.43 & 0.16 & 0.04 \\
WAIS-III: Vocabulary & 0.27 & 0.05 & & & 0.27 \\
\hline
\end{tabular}

RAVLT: Rey auditory verbal learning test; WAIS-III: Wechsler adult intelligence scale. * ${ }^{p}$-values.

frequency of depressive disorder, generalized anxiety disorder, non-repairing sleep and hypothyroidism. However, after linear regression analysis, these comorbidities no longer influenced the cognitive performance of the patients. The cited study was the first conducted in Brazil on chronic pain and cognition, with emphasis on the fact that this research area is still a great challenge ${ }^{31}$.

Several studies have assessed the association between migraine and cognitive function; nevertheless, most of them did not evaluate CM specifically. Some large studies found evidence of worse cognitive performance among patients with migraine without aura and controls ${ }^{13,14,15}$, and others evaluated cognitive decline over time in elderly men and women with migraine ${ }^{18,19}$. Different tests were used to evaluate cognitive function, without a pattern.

Specifically regarding the relationship between $\mathrm{CM}$ and cognition, one study evaluated patients with migraine and control patients using the Mini-Mental State Examination and MoCA test and detected a poorer performance by migraine patients in the MoCA, but not in the Mini-Mental State Examination. No other tests were carried out to assess cognition in general, executive functions, language processing, delayed recall, visuospatial functions or inhibitory control. In addition, the influence of factors such as psychiatric disorders, sleep disorders and use of medications was not investigated ${ }^{12}$.

The exact mechanism underlying the complex relationship between chronic pain and cognition is not fully understood. There is a direct relationship between attention, transient retention of information, immediate memory and the activity of the prefrontal cortex nuclei. What are the physiological bases of this finding? Firstly, the neural networks that are engaged for many cognitive functions are also used for nociceptive functions. Secondly, physical sensations can lead a person to a state of hypervigilance and shift his attention from other cognitive tasks, impairing an effective response to new information. These findings support the "neurocognitive model of the pain-attention dynamics", supporting the idea that patients with chronic pain have maladaptive neuroplasticity that may manifest clinically as a cognitive deficit ${ }^{6}$.

Clinical studies involving chronic pain and cognition face important difficulties such as controlling confounding factors that influence cognitive performance and are present in patients with chronic pain, such as psychiatric disorders, sleep disorders, use of analgesics and pain prevention medications, etiology of pain or patient age and lifestyle. Thus, studies in this field involve a complex statistical analysis and represent a challenge ${ }^{32}$.

A differential aspect of our study was the evaluation not only of memory and attention, but also of language and visuospatial skills using an extended neuropsychological assessment. In addition, the main variables that might influence the performance of patients with $\mathrm{CM}$ in neuropsychological tests were analyzed with specific statistical models. Thus, we believe that the present study adds original information to the literature on this topic. Regarding strengths and limitations of the study, our main limitation was the number of patients. However, although the number of patients was small, we were able to work with a sample matched for age, sex and schooling, and we used a linear regression model to control possible confounding variables. Thus, the present findings lead us to believe that the relationship between CM and cognitive deficits represents a genuine reality in the daily routine of neurologists who work with the treatment of headaches. Considering unanswered questions about this subject, future studies should also investigate cognitive deficits in patients with episodic migraine and the exact moment when they appear, in a longitudinal evaluation.

Another limitation of the study was the lack of a brain MRI of the participants, to evaluate structural brain lesions and white matter hyperintensities, which have been associated with both migraine and cognitive decline. This could also be measured in future studies.

As a clinical implication of these findings, we propose a more active search of cognitive deficits in patients with $\mathrm{CM}$ 
be carried out, possibly including a brief neuropsychological evaluation of these patients. Once we detect these deficits, we can optimize the treatment of the patients. In addition, there are strategies for cognitive interventions to improve these deficits that go beyond the treatment of pain itself and of depressive and anxiety disorders. Thus, patients diagnosed with these deficits would benefit from "cognitive training", improving their quality of life ${ }^{23}$.

\section{References}

1. Rasmussen BK. Epidemiology of headache. Cephalalgia. 2001 Sep;21(7):774-7. https://doi.org/10.1177/033310240102100708

2. Becker WJ, Gladstone JP, Aubé M. Migraine prevalence, diagnosis, and disability. Can J Neurol Sci. 2007 Nov;34(4):S3-9.

3. The International Classification of Headache Disorders: 3 nd edition. Cephalalgia, 2013;33(9):644-58.

4. Giacomozzi AR, Vindas AP, Silva AA Jr, Bordini CA, Buonanotte CF, Roesler CA, et al. Latin American consensus on guidelines for chronic migraine treatment. Arq Neuropsiquiatr. $2013 \mathrm{Jul} ; 71(7): 478-86$. https://doi.org/10.1590/0004-282X20130066

5. Schwedt TJ, Dodick DW.Advanced neuroimaging of migraine. Lancet Neurol. 2009 Jun;8(6):560-8. https://doi.org/10.1016/S1474-4422(09)70107-3

6. Aurora SK, Brin MF. Chronic migraine: an update on physiology, imaging, and the mechanism of action of two available pharmacologic therapies. Headache. 2017 Jan;57(1):109-25. https://doi.org/10.1111/head.12999

7. McKendrick AM, Badcock DR, Badcock JC, Gurgone M. Motion perception in migraineurs: abnormalities are not related to attention. Cephalalgia. 2006 Sep;26(9):1131-6. https://doi.org/10.1111/j.1468-2982.2006.01182.x

8. Leijdekkers ML, Passchier J, Goudswaard P, Menges LJ, Orlebeke JF. Migraine patients cognitively impaired? Headache. 1990 May;30(6):3528. https://doi.org/10.1111/j.1526-4610.1990.hed3006352.x

9. Gaist D, Pedersen L, Madsen C, Tsiropoulos I, Bak S, Sindrup S et al. Long-term effects of migraine on cognitive function: a populationbased study of Danish twins. Neurology. 2005 Feb;64(4):600-7. https://doi.org/10.1212/01.WNL.0000151858.15482.66

10. Jelicic M, van Boxtel MP, Houx PJ, Jolles J. Does migraine headache affect cognitive function in the elderly? Report from the Maastricht Aging Study (MAAS). Headache. 2000;40:715-719. https://doi.org/10.1212/01.WNL.0000151858.15482.66

11. Pearson AJ, Chronicle EP, Maylor EA, Bruce LA. Cognitive function is not impaired in people with a long history of migraine: a blinded study. Cephalalgia. 2006 Jan;26(1):74-80. https://doi.org/10.1111/j.1468-2982.2005.01001.x

12. Santos-Lasaosa S, Viloria-Alebesque A, Morandeira-Rivas C, Lopez Del Val LJ, Bellosta-Diago E, Velazquez-Benito A. [Mnemonic complaints and chronic migraine]. Rev Neurol. 2013 Aug;57(4):145-9. Spanish.

13. Hooker WD, Raskin NH. Neuropsychologic alterations in classic and common migraine. Arch Neurol. 1986 Jul;43(7):709-12. https://doi. org/10.1001/archneur.1986.00520070065020

14. Zeitlin C, Oddy M. Cognitive impairment in patients with severe migraine. Br J Clin Psychol. 1984 Feb;23(Pt 1):27-35. https://doi. org/10.1111/j.2044-8260.1984.tb00623.x

15. Pellegrino Baena C, Goulart AC, Santos IS, Suemoto CK, Lotufo PA, Bensenor IN. Migraine and cognitive function: Baseline findings from the Brazilian longitudinal study of adult health: ELSA-
Brasil. Cephalalgia 2017 Jan 1:333102417737784. https://doi. org/10.1177/0333102417737784

16. Yasuda CL, Centeno M, Vollmar C, Stretton J, Symms M, Cendes F et al. The effect of topiramate on cognitive fMRI. Epilepsy Res. 2013 Jul;105(1-2):250-5. https://doi.org/10.1016/j.eplepsyres.2012.12.007

17. Loring DW, Williamson DJ, Meador KJ, Wiegand F, Hulihan J. Topiramate dose effects on cognition: a randomized double-blind study. Neurology. 2011 Jan;76(2):131-7. https://doi.org/10.1212/WNL.0b013e318206ca02

18. Rist PM, Kurth T. Migraine and cognitive decline: a topical review. Headache. 2013 Apr;53(4):589-98. https://doi.org/10.1111/head.12046

19. Rist PM, Dufouil C, Glymour MM, Tzourio C, Kurth T. Migraine and cognitive decline in the population-based EVA study. Cephalalgia. 2011 Sep;31(12):1291-300. https://doi.org/10.1177/0333102411417466

20. American Psychiatry Association. Diagnostic and statistical manual of mental disorders - DSM - 5. 5th ed. Washington: American Psychiatric Association; 2013.

21. Freitas S, Simões MR, Martins C, et al. Estudos de validação do Montreal Cognitive Assessment (Moca) para a população portuguesa. Aval Psi., 2010;9(3):345-57.

22. Stroop R. Studies interference in serial verbal reactions.J Exp Psychol. 1935;18(6):643-62. https://doi.org/10.1037/h0054651

23. Rabelo IS, Pacanaro SV, Rossetti MO, Leme IFAS. Teste das Trilhas Coloridas: manual profissional. São Paulo: Casa do Psicólogo; 2010.

24. Malloy-Diniz LF, Cruz MF, Torres V, Cosenza R. O teste de Aprendizagem Auditivo-Verbal de Rey: normas para uma população brasileira. Rev Bras Neurol. 2000;36(3):79-83.

25. Nascimento E. Adaptação, validação e normatização do WAIS-III para uma amostra brasileira. In: Wechsler D, editor. WAIS-III: manual para administração e avaliação. São Paulo: Casa do Psicólogo; 2004.

26. Beck AT, Epstein N, Brown G, Steer RA. An inventory for measuring clinical anxiety: psychometric properties. J Consult Clin Psychol. 1988 Dec;56(6):893-7. https://doi.org/10.1037/0022-006X.56.6.893

27. Beck AT, Ward CH, Mendelson M, Mock J, Erbaugh J. An inventory for measuring depression. Arch Gen Psychiatry. 1961 Jun;4(6):561-71. https://doi.org/10.1001/archpsyc.1961.01710120031004

28. SAS/ STAT User's guide, Version 8. Cary, NC: SAS Institute Inc., 1999. R version 2.8.0 copyright? 2008.

29. Landrø NI, Fors EA, Våpenstad LL, Holthe $\emptyset$, Stiles TC, Borchgrevink PC. The extent of neurocognitive dysfunction in a multidisciplinary pain centre population. Is there a relation between reported and tested neuropsychological functioning? Pain. $2013 \mathrm{Jul}$;154(7):972-7. https://doi.org/10.1016/j.pain.2013.01.013

30. Ferreira KS, Oliver GZ, Thomaz DC, Teixeira CT, Foss MP. Cognitive deficits in chronic pain patients, in a brief screening test, are independent of comorbidities and medication use. Arq Neuropsiquiatr. 2016 May;74(5):361-6. https://doi.org/10.1590/0004-282X20160071 